\title{
ANNOTATIONS
}

\section{Mass Testing of Colour Vision}

Berens and Stein have devised an ingenious method of testing the colour vision of a large number of persons at one session and thereby effecting a considerable saving of time. It is a method that would be of some service in examining groups of applicants for appointments in those branches of the public services (civil servants, mariners, aviators and railway employees) in which certain standards of colour vision are necessary and it might well be extended to some industrial occupations, to drivers of motor vehicles and to schools.

The standard colour vision charts of Ishihara and Stilling are photographed with a $35 \mathrm{~mm}$. Kodaclirome film and then copied by a miniature camera, used in conjunction with the copring accessories, and made into $2 \times 2$ inch lantern slides. These when thrown on to a glass bead screen by a miniature lantern slide projector gave results identical with the control tests on the original test plates.

The examination is carried out in a semi-darkened room and each candidate has a printed slip with key numbers corresponding to the order in which the slides are projected and opposite each number he notes the figure he identifies on pseudo-isochromatic charts projected on the screen.

Ishihara and Stilling slides may be interchanged or the order varied in making repeated or annual examinations.

The malingering tests, threshold tests after the Young method, the Edridge Green and other lantern tests, Worth's four dot test and its modifications and the kindergarten chart may be projected.

Visual acuity need not be normal for these tests for the images are easily magnified.

Berens and Stein suggest that by this method it may be possible to educate colour blind persons to differentiate various colours in coloured slides of scenes.

Such mass testing of colour vision from time to time would also have the advantage of revealing disturbances of colour vision due to toxic amblyopia and optic neuritis.

Berens, C., and Stein, L.-Jl. Amer. Med. Assoc., Vol. CXIII, p. 1563, 1939.

\section{Some Ophthalmic Army Problems}

The following facts which have been given us by an ophthalmic surgeon of acknowledged reputation will, we think, be of interest to our readers and are worth the consideration of the authorities.

Among 267 soldiers examined for errors of refraction between September 14, 1939, and March 13, 1940, amblyopia of the right 